\title{
Occupational stereotypes: professionals' warmth and competence perceptions of occupations
}

Andrea Strinić

Department of Psychology, Faculty of Health and Life Sciences, Linnaeus University, Växjö, Sweden

Magnus Carlsson

Department of Economics and Statistics, School of Business and Economics, Linnaeus University, Kalmar, Sweden, and

Jens Agerström

Department of Psychology, Faculty of Health and Life Sciences, Linnaeus University, Kalmar, Sweden

\begin{abstract}
Purpose - The purpose of the current study is to investigate occupational stereotypes among a professional sample of recruiters and other employees on the two fundamental dimensions of warmth and competence.

Design/methodology/approach - The authors conducted a survey to collect professionals' (mostly recruiters') ratings of preselected occupations. Participants were asked to rate warmth and competence attributes. Factor and cluster analysis were employed to investigate the two-dimensional structure of the warmth/competence space and how and whether occupations cluster as predicted by the stereotype content model (SCM).

Findings - Almost all occupations showed a clear two-factorial structure, corresponding to the warmth/ competence dimensions. A five-cluster solution was deemed appropriate as depicting how occupations disperse on these dimensions. Implications for stereotyping research, the design of hiring discrimination experiments, and HRM are discussed.

Originality/value - In contrast to previous related research, in which participants select the included occupations themselves, the authors included prespecified common occupations, which should be important for representativeness. In addition, previous research has been conducted in the United States, while the authors conduct this study in a European context (Sweden). Finally, instead of studying students or participants with unspecified work experience, the authors focus on professionals (mostly recruiters).
\end{abstract}

Keywords Warmth, Competence, Stereotype content model, Occupational stereotypes, Hiring

Paper type Research paper

\section{Introduction}

We want our surgeons to seem competent, and a cold preschool teacher might leave us worried. People generally have expectations of how a typical employee in an occupation behaves. In recent decades, stereotype content model (SCM) has identified cross-culturally cutting dimensions of social judgment, claiming that individuals and groups will be seen in

(C) Andrea Strinić, Magnus Carlsson and Jens Agerström. Published by Emerald Publishing Limited. This article is published under the Creative Commons Attribution (CC BY 4.0) licence. Anyone may reproduce, distribute, translate and create derivative works of this article (for both commercial and noncommercial purposes), subject to full attribution to the original publication and authors. The full terms of this licence may be seen at http://creativecommons.org/licences/by/4.0/legalcode

This research was supported by the Swedish Research Council (Grant no. 2018-03487). The funder has had no role in the research process.

Received 3 July 2020 Revised 1 November 2020 Accepted 28 December 2020

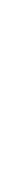


PR

51,2

\section{4}

terms of how warm and competent they are (e.g. elderly are seen as warmer and less competent) (Cuddy et al., 2009; Fiske et al., 1999, 2002). The warmth dimension relates to the intent of the perceived group, more specifically, traits depicting friendliness, helpfulness, sincerity, while the competence dimension reflects capability, and associated attributes such as intelligence, and ambitiousness (Fiske et al., 2007). This model has gone beyond perceptions of groups and individuals and found that warmth and competence can account for perceptions of intention having entities like brands and companies (Kervyn et al., 2012), as well as occupations (Fiske and Dupree, 2014; He et al., 2019; Imhoff et al., 2013).

\section{Content of occupational stereotypes}

Although research on the stereotype content of demographic groups has been prolific with numerous cross-cultural replications (e.g. Bye et al., 2014; Cuddy et al., 2009), research on the stereotype content of occupations is still in its infancy. To our knowledge, only one study, Fiske and Dupree (2014), has explicitly tested the SCM in the context of occupations. They followed the typical SCM procedure and asked 48 participants to mention common jobs they could think of, which were then rated by an additional 116 participants. In total, 42 jobs (e.g. scientist, teacher and childcare worker) were rated on perceived warmth and competence. The results supported main tenets of SCM, showing that perceived warmth/competence could differentiate job categories, that some jobs had ambivalent stereotypes ascribed and that ratings of warmth/ competence have social structure correlates (social status/competitiveness).

Rather than focusing on how occupations disperse on the warmth/competence space and its structure, He et al. (2019) were interested in whether labor market outcomes could be predicted from stereotype content. Specifically, they demonstrated that occupational segregation is related to incongruences between demographic and occupational stereotypes. For example, they found that women, who are stereotyped as possessing more warmth but less competence than men, are more represented in occupations characterized by high warmth and low competence. Conversely, Asians, who are stereotyped as being highly competent but not as warm, were more represented in occupations characterized by high competence.

Some research has also studied occupational stereotypes using different conceptualizations of stereotype content. Drawing on the social role theory (Eagly and Wood, 2012) as a theoretical framework, Koenig and Eagly (2014) propose that people's observations of groups' social roles determine stereotype content in terms of agency and communion. To illustrate, because women are more frequently observed in roles that involve taking care of children than men, both at home and in the workplace, people infer that women as a group must possess more communal traits, such as social sensitivity and nurturance. Consistent with the social role theory, Koenig and Eagly (2014) found that people's beliefs about the attributes of occupational groups' typical roles strongly predict agency and communion stereotypes. Although there is a clear overlap between agency/communion and competence/warmth, the concepts are distinct with, for example, agency/communion being highly synonymous with masculinity/femininity.

Imhoff et al. (2018) were also interested in correspondence between stereotype dimensions about occupations and stereotypes about social groups. Rather than having the participants rate occupations on preestablished stereotype dimensions, they asked participants to rate and compare occupations on stereotype dimension(s) that spontaneously came to their mind. They then used a data-driven approach to compute cognitive models of the occupations and conclude that the stereotype dimensions spontaneously employed to make sense of occupational groups (agency; progressiveness) align well with people's stereotypes about social groups.

\section{Occupational stereotypes and hiring}

The notion of occupational stereotypes also appears in the literature on preferential treatment and hiring discrimination. Researchers have used lab and field experiments to examine how 
applicants from various social groups are treated when applying for jobs that differ with respect to how much client contact and cognitive demands they require (Derous et al., 2009, 2015, Weichselbaumer, 2016). Researchers have also investigated preferential treatment based on the social status of the occupation, the type of job and job tasks and whether the job is male or female dominated (Derous et al., 2017; Goldberg et al., 2004; King et al., 2006; Krings et al., 2011; Ruggs et al., 2014). Although all these approaches have provided valuable insight into the treatment and preferences of various social groups, one could argue that they have not systematically addressed the variety of stereotypes associated with both occupations and social groups and how such stereotypes might relate to hiring preferences. For example, correspondence tests have shown that women may receive a comparatively higher callback rate for an interview in female-dominated occupations (Booth and Leigh, 2010; Carlsson, 2011). On the other hand, Farber et al. (2017) similarly focused only on occupations where women are overrepresented, used only female applicants and still noted a drop in callback rates for women 50 years and older. Although one line of research showed that women could have an advantage in female-dominated jobs, another line shows that if age is accounted for, further differences in similar occupations emerged. This research illustrates the type of situations where being able to account for more characteristics of both the occupation and the applicant may lead to further predictions that may capture more subtle differences. It has been proposed that applying the SCM to occupations may provide a more comprehensive picture of occupational stereotypes. According to He et al. (2019), warmth/competence dimensions cut across several usual dimensionalities ascribed to occupations, such as status and prestige, gender and personality type.

Baert (2018) aimed to make a comprehensive list of correspondence tests on hiring discrimination and identified 90 experiments conducted between 2005 and 2016. Overall it was found that 80 experiments find a significant treatment effect, reflecting discriminatory treatment of minority groups. Interestingly, 57 of the identified experiments have been conducted in Europe (e.g. Belgium, Sweden and France). Having knowledge about specific occupational stereotypes in a European context might be useful if one wants to understand the potential mechanisms underlying the hiring discrimination that affect various demographic groups (e.g. Arabs, women/men and gay people) in Europe.

\section{The current research}

Akin to traditional SCM research (Cuddy et al., 2009; Fiske et al., 2002) on demographic groups (e.g. women and poor people), the current study employs cluster analysis to explore whether the two-dimensional warmth/competence space applies to occupational stereotypes in a European country (Sweden). Unlike most previous research on occupational stereotypes relying on research participants' own selection of occupations, we study warmth and competence perceptions of the largest and most common occupations, using the Swedish Standard Classification of Occupations (which follows the International Classification of Occupations (ISCO-08), see https:/www.ilo.org/public/english/bureau/stat/isco/isco08/) as a basis for selecting occupations. Besides allowing for a clustering of occupations in the warmth and competence space, this study compares individual occupations within the clusters.

Virtually all previous studies on occupational stereotypes (reviewed above) have been conducted in the United States. The only exception seems to be the Imhoff et al. (2013) study, which was partly conducted in Germany. Bear in mind, however, that it did not examine how occupational stereotypes disperse on the warmth/competence space. The SCM posits that the warmth and competence dimensions are universal, but the way demographic groups disperse on the warmth/competence space could differ across cultures depending on the group's perceived status and competitiveness (Fiske et al., 2002). This could also be the case for
Occupational stereotypes

605 
PR

51,2

\section{6}

occupational warmth and competence stereotypes, and therefore a test of the SCM in a European context seems warranted.

Previous work on occupational stereotypes has used student or MTurk participants with unspecified work experience. It is thus unclear from previous research whether warmth and competence occupational stereotypes are also harbored by working professionals. To address this limitation of the literature, the current study examines occupational stereotypes in a professional sample consisting mostly of recruiters. Examining occupational stereotypes in this population is important in relation to human resource management (HRM) because they are presented with many opportunities to enact on their stereotypes; for example, in conjunction with selection and assessment.

The aims of the current study are to investigate how preselected occupations with high relevance for the labor market are perceived by a professional sample consisting mostly of recruiters, how these occupations disperse on the warmth and competence space and how warmth and competence perceptions vary depending on occupation.

\section{Method}

A similar methodological approach to that of the method employed by Fiske et al. (2002) and Cuddy et al. (2009) to investigate SCM's theoretical assumptions was used. Factor and cluster analysis were employed to investigate the two-dimensional structure of the warmth/ competence space and to explore how and whether occupations cluster as predicted by SCM. In order to compare occupations between and within clusters, $t$-tests were employed. Previous SCM research (e.g. Fiske et al., 2002) has used $t$-tests to explore an indication of mixed stereotype content (that is, having a higher score on one compared to the other dimension).

\section{Participants}

A convenience sample of 130 (women $=87$, men $=41$; average age $=41, \mathrm{SD}=12.49$, range 21-70 years of age) recruiters and employees answered the questionnaire. The main criterion for participant selection was that they had to be employed, preferably working with recruitment processes and hiring. Out of 130 participants, 89 declared that they were employed as recruiters (average length of recruitment work experience was 8.79, $\mathrm{SD}=7.93$ years and work experience ranged from 6 months to 30 years). Examples of current positions held by the remaining participants were various manager and CEO positions and employment agency positions. Only eight participants (in addition to five missing cases) stated that they did not have any experience of working with recruitment.

\section{Instruments}

We used a warmth and competence survey, which was largely based on survey originally employed by Cuddy et al. (2009), when examining the SCM model across cultures. The survey was slightly modified to fit a Swedish context [1]. A five-point Likert scale (1 "not at all" -5 "extremely") was used for both the warmth and competence subscales. Participants were asked to rate warmth (friendliness, warmth, benevolence and considerateness) and competence attributes (talent, competence, skill and ambition) for various occupations. The participants were asked for general perceptions of how these attributes relate to occupational categories. We also collected data on age, gender, birthplace, length of stay in Sweden, recruiting experience and current work position [2].

\section{Procedure}

Official company websites, local businesses, job fairs and professional gatherings were used to recruit participants. No restrictions were made considering the type of company, its size or 
its physical location. The majority of participants were found through online official websites of businesses and were sent an email with a link to the online survey hosted with Qualtrics software. A smaller number of participants were approached at job fairs and professional meetings and were given a pen and paper version of the survey to complete. The participants were told that the study was about recruitment processes and that the main aim was to understand how different work-related characteristics of groups in society are perceived. To minimize social desirability bias, we followed Fiske $e t$ al. (2002) and asked the respondents to report general perceptions and not personal opinions. To increase the response rate, a reward of two movie tickets was offered, which 79 participants claimed and received.

\section{Occupations}

A list of the 30 largest occupations in Sweden (based on the number of workers being 16-74 years old, Statistics Sweden, 2015) was used as the basis for the selection of occupations to be rated. The focus was on selecting occupations that are common, as knowing stereotypes associated to these occupations may be useful for further investigation into hiring processes. This list covers diverse occupations that require different levels of requirements (e.g. cleaner, sales person, preschool teacher and software developer). Prior to data collection, some occupations on the list were deemed similar or related to each other (e.g. different types of sales jobs) and were thus merged into corresponding general categories (e.g. salesperson). Two relatively common occupations (researcher and surgeon) that were related to some of the occupations on the list were added in an attempt to evoke stereotypes from all quadrants of the SCM space (Fiske et al., 2002). These adjustments resulted in 22 occupations to be rated by participants.

\section{Survey presentation strategy}

The occupations to be rated were divided in two sets in order to make the survey shorter and efficient. Each participant rated only one set consisting of 11 occupations. The order in which the two sets of occupations appeared was counterbalanced. Having half of the participants rate different occupations was considered acceptable, as the unit of analysis is the occupation itself (see Cuddy et al., 2009; Fiske et al., 2002).

\section{Results}

\section{Preliminary analysis}

An exploratory factor analysis was conducted to assess the warmth/competence factorial structure and to create predictor scales across occupational categories. Out of 22 occupations, 21 had a clear two-factor solution with eigenvalues larger than one, which explained from $53 \%$ to $72 \%$ of the total variance. The truck driver was the only occupational category that did not have a clear two-factor solution. Cronbach's alpha for the warmth subscale ranged from 0.69 to 0.91 , and for the full sample it was 0.90 . For the competence subscale, Cronbach's alpha ranged from 0.74 to 0.92 , and for the full sample it was 0.90 . Almost all preselected occupations showed a two-factorial structure consistent with the SCM, which allowed us to investigate further their characteristics and positioning within the warmth/ competence space.

\section{Overview of warmth and competence scores for occupations}

Warmth and competence scores were created by averaging each subscale into one mean score for each occupational group. The competence scores ranged from 2.47 to 4.52 and warmth scores from 2.49 to 4.33 . The mean scores for each occupational category on both warmth and competence were centered on the rating 3 . This calculation served to examine the extent to
Occupational stereotypes 
PR

51,2

608

which mean scores diverged from the middle of the scale. For warmth, this was from -0.51 to 1.33 , and for competence it was from -0.53 to 1.52 . Both warmth and competence showed a similar diversification of groups. The variation of the mean scores for occupations was more limited in the lower end of the scale, with the ratings above mid-point of the scale indicating higher ratings on the dimensions showing a wider range.

The highest warmth score in the entire sample was given to the preschool teacher $(M=4.33 ; \mathrm{SD}=0.59)$. In contrast, the lowest warmth score was given to the truck driver category $(M=2.49 ; \mathrm{SD}=0.82)$. The highest competence score was given to category surgeon $(M=4.52 ; \mathrm{SD}=0.64)$, while the lowest to the warehouse worker category $(M=2.47$; $\mathrm{SD}=0.78)($ Table 1$)$.

Warmth and competence structure of occupational categories

Following the typical analytical approach in SCM research (Fiske et al., 2002; Cuddy et al., 2009) and statistical recommendations by Hair et al. (2019), a hierarchal and $k$-means cluster analysis was conducted to explore the structure of occupational stereotypes in terms of the warmth and competence dimensions. Hierarchal cluster analysis with the Wards method clustering algorithm and squared Euclidian distance measure were used to determine the initial number of clusters. Percentage change in heterogeneity as a stopping rule was applied to determine the initial number of cluster solutions. Agglomeration schedule contains

\begin{tabular}{lcccc}
\hline Occupation & Warmth & SD & Competence & SD \\
\hline Survey version 1 & & & & \\
Assistant nurse, home-help service, home health nursing and & 4.07 & 0.72 & 3.11 & 0.75 \\
retirement home workers & & & & \\
Salesperson & 2.84 & 0.70 & 3.28 & 0.69 \\
Surgeon & 3.11 & 0.88 & 4.52 & 0.64 \\
Engineer & 2.92 & 0.56 & 4.34 & 0.56 \\
Chef & 3.12 & 0.60 & 3.59 & 0.64 \\
Store manager & 3.28 & 0.59 & 3.45 & 0.64 \\
Warehouse worker & 2.59 & 0.58 & 2.47 & 0.78 \\
Assistant accountant & 3.06 & 0.61 & 3.20 & 0.60 \\
High-school teacher & 3.61 & 0.60 & 3.64 & 0.59 \\
Cleaning staff & 3.08 & 0.81 & 2.49 & 0.90 \\
Mechanic & 2.63 & 0.65 & 3.13 & 0.80 \\
Survey version 2 & & & & \\
Accountant & & & & 0.64 \\
Staff nurse & 2.61 & 0.82 & 3.87 & 0.63 \\
Carpenter & 4.29 & 0.65 & 3.87 & 0.66 \\
Heavy machinery operator & 2.88 & 0.68 & 3.47 & 0.75 \\
Office assistants and secretaries & 2.61 & 0.76 & 3.27 & 0.69 \\
Truck driver & 3.46 & 0.65 & 3.17 & 0.87 \\
Researcher & 2.49 & 0.82 & 2.72 & 0.52 \\
Systems and software developer & 2.55 & 0.72 & 4.52 & 0.57 \\
Restaurant waiting staff & 2.52 & 0.82 & 4.19 & 0.73 \\
Preschool teacher & 3.59 & 0.73 & 2.83 \\
Personal assistants & 4.33 & 0.59 & 3.45 & 0.77 \\
Note(s): Occupations & 4.15 & 0.61 & 3.00 & 0.83
\end{tabular}

Table 1.

Mean warmth and competence scores for occupational categories
Note(s): Occupations in Swedish following the order of presentation are as follows: undersköterskor, hemtjänst, hemsjukvård och äldreboende; säljare; kirurg; civilingenjör; kock, butikschef, lagerarbetare, ekonomiassistent, gymnasielärare, städare, mekaniker; redovisningsekonom; sjuksköterska, snickare; maskinoperatör; kontorsassistent och sekreterare; lastbilsförare; forskare; mjukvaru- och systemutvecklare, serveringspersonal (restaurang); förskollärare; personliga assistenter 
information about which cases have been merged at which stage and provides coefficients that show the distances between each stage (Fiske et al., 2002). According to Hair et al. (2019), small coefficients indicate more homogenous clusters being merged, while large coefficients indicate that heterogeneous or different clusters have been merged. Coefficients tend to be larger at the end of the agglomeration schedule. The percentual increase or "jump" from one to the other coefficient for the last couple of stages was calculated and examined. The largest jump in dissimilarity was in the transition from four to three-cluster solution, with the increase in heterogeneity being $33.71 \%$. In addition to two and three cluster solutions that were expected to have a more substantial increase than the rest, the transition from a fivecluster to a four-cluster solution had a reasonably large coefficient corresponding to an $26.88 \%$ increase. Agglomeration coefficients were then plotted on a scree plot. Both five and four cluster solutions were visually indicating a jump in dissimilarity. Before proceeding with nonhierarchal clustering, a profiling of the four and five cluster solution was conducted. Oneway ANOVA showed significant differences for a four-cluster solution for both warmth $(F=17.647 ; p=0.000)$ and competence $(F=29.407 ; p=0.000)$ indicating possible distinctiveness of all four cluster solutions. A five-cluster solution also showed significant differences in warmth $(F=15.847 ; p=0.000)$ and competence $(F=39.461 ; p=0.000)$. Mean values for each cluster solution were examined, and a five-cluster solution was considered as providing the most distinctive solution that would be of relevance for the study (Figure 1).

The $k$-means cluster analysis was used to examine which occupational categories belong to which clusters. The five-cluster solution was compared to four, three and two cluster solutions, as hierarchal cluster analysis indicated these as having potentially relevant "jumps" in dissimilarity. These comparisons were also conducted to investigate the stability of occupations by marking which occupations fit together across solutions (Table 2). A matched pair $t$-test for each cluster's warmth and competence mean scores was conducted to explore if there is an indication of a mixed stereotype cluster. A one-way ANOVA with subsequent Tukey's post hoc tests were performed to determine whether the clusters were significantly different from one another.

Cluster 1 [3] had a mean score that was higher in warmth than competence and comprised five occupations that were sorted together across solutions. It contained the following: assistant nurse, office assistants and secretaries, personal assistant and restaurant waiting staff. High-school teacher was almost consistent except that if a four-cluster solution was used it would cluster differently. Matched pair $t$-test on cluster center shows that this cluster is significantly higher in warmth $(M=3.78)$ than competence $(M=3.15), t(4)=2.859, p=0.046$. Cluster 2 had the lowest score on both warmth and competence for the entire sample. Warehouse worker, cleaning staff and truck driver appeared together across solutions (Table 2). Their warmth $(M=2.72)$ and competence score $(M=2.56)$ indicate a cluster that is low on both dimensions $t(2)=0.672, p=0.571$. Cluster 3 contains seven occupations. Out of those, five occurred together in all tested solutions: assistant accountant, mechanic, salesperson, heavy machinery operator and carpenter. Occupations chef and store manager are not as consistent with different solutions. This cluster is characterized by significantly higher competence $(M=3.34)$ than warmth $(M=2.92), t(6)=-5.661, p=0.001$. A small cluster 4 emerges with higher warmth $(M=4.31)$ than competence $(M=3.66)$, but the difference was not significantly higher $(t(1)=2.832 ; p=0.216)$. The occupations belonging to this cluster and that consistently group together across cluster solutions are preschool teacher and staff nurse. This cluster did have the highest warmth of the sample. As the scores on both warmth and competence are relatively high, this cluster could be regarded as the high warmth and high competence cluster. Engineer, surgeon, researcher, systems and software developer and accountant clustered together in Cluster 5 across all solutions except for the last two occupational categories in the last two-cluster solution. Due to the categories mostly appearing together consistently, this can be regarded as quite a stable solution. This solution
Occupational stereotypes

609 
PR

51,2

610

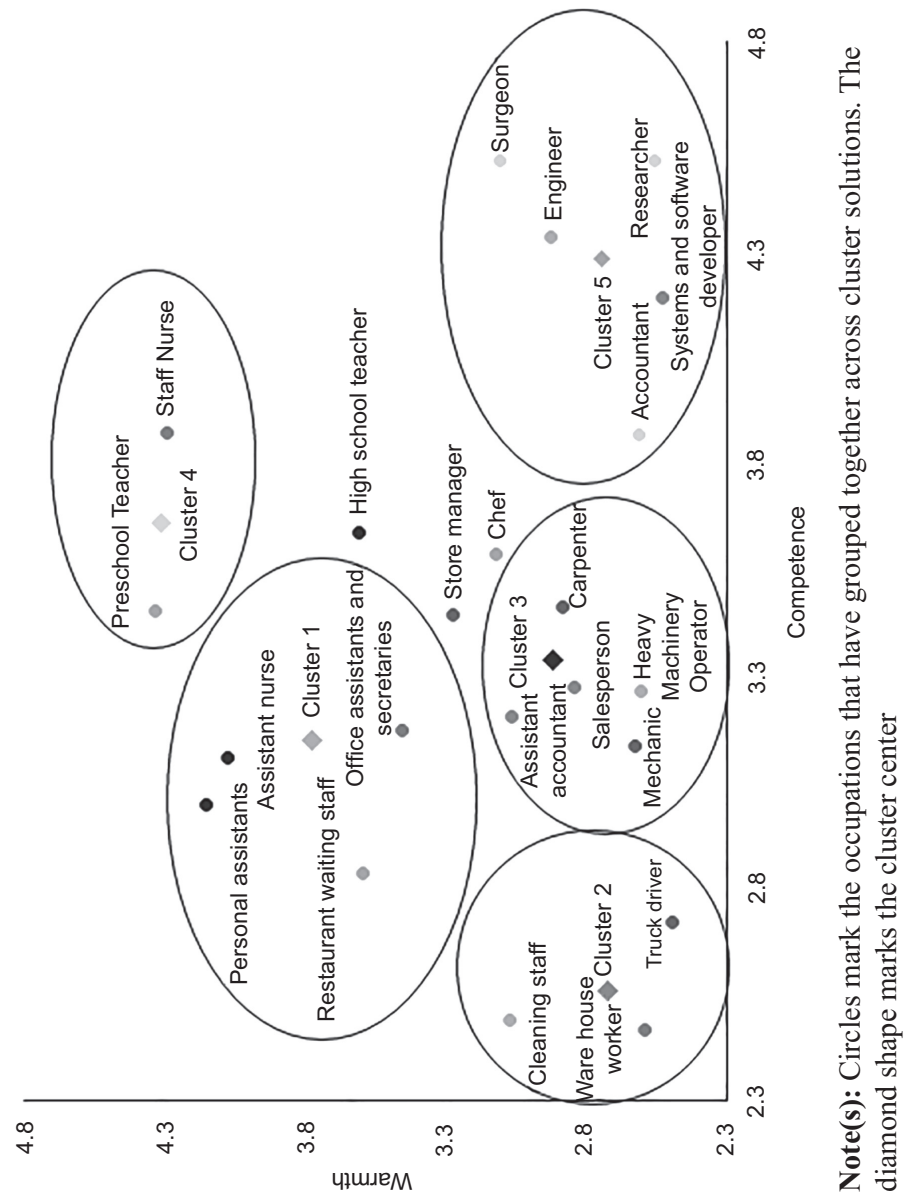

Figure 1.

Five cluster solution of the occupational categories 


\begin{tabular}{|c|c|c|c|c|c|c|c|}
\hline \multirow[b]{2}{*}{ Occupations } & \multicolumn{4}{|c|}{$\begin{array}{l}\text { Cluster } \\
\text { solution }\end{array}$} & \multicolumn{3}{|c|}{ Cluster center mean } \\
\hline & 5 & 4 & 3 & 2 & Competence & & Warmth \\
\hline $\begin{array}{l}\text { Assistant nurse, home-help service, home health } \\
\text { nursing and retirement home workers }\end{array}$ & 1 & 3 & 1 & 2 & $3.15 \mathrm{a}$ & $p=0.046$ & $3.78 \mathrm{a}$ \\
\hline Office assistants and secretaries & 1 & 3 & 1 & 2 & & & \\
\hline Personal assistants & 1 & 3 & 1 & 2 & & & \\
\hline Restaurant waiting staff & 1 & 3 & 1 & 2 & & & \\
\hline High-school teacher & 1 & 4 & 1 & 2 & & & \\
\hline Warehouse worker & 2 & 1 & 3 & 1 & $2.56 \mathrm{~b}$ & $p=0.571$ & $2.72 b$ \\
\hline Cleaning staff & 2 & 1 & 3 & 1 & & & \\
\hline Truck driver & 2 & 1 & 3 & 1 & & & \\
\hline$\overline{\text { Assistant accountant }}$ & 3 & 1 & 3 & 1 & $3.34 \mathrm{a}$ & $p=0.001$ & $2.92 \mathrm{~b}$ \\
\hline Mechanic & 3 & 1 & 3 & 1 & & & \\
\hline Salesperson & 3 & 1 & 3 & 1 & & & \\
\hline Heavy machinery operator & 3 & 1 & 3 & 1 & & & \\
\hline Carpenter & 3 & 1 & 3 & 1 & & & \\
\hline Chef & 3 & 1 & 2 & 2 & & & \\
\hline Store manager & 3 & 3 & 1 & 2 & & & \\
\hline Preschool teacher & 4 & 4 & 1 & 2 & $3.66 \mathrm{a}$ & $p=0.216$ & $4.31 \mathrm{a}$ \\
\hline Staff nurse & 4 & 4 & 1 & 2 & & & \\
\hline Engineer & 5 & 2 & 2 & 2 & $4.29 \mathrm{c}$ & $p=0.000$ & $2.74 \mathrm{~b}$ \\
\hline Surgeon & 5 & 2 & 2 & 2 & & & \\
\hline Researcher & 5 & 2 & 2 & 2 & & & \\
\hline Systems and software developer & 5 & 2 & 2 & 1 & & & \\
\hline Accountant & 5 & 2 & 2 & 1 & & & \\
\hline
\end{tabular}

Note(s): Italic typeface indicates occupations that have consistently appeared together across all four types of solutions. Within each column the clusters that have the same subscript do not differ with a $p<0.05$ level

Table 2.

Occupations across cluster solutions and means for the fivecluster solution

indicates high competence $(M=4.29)$ and low warmth $(M=2.74), t(4)=-12.449, p=0.000$. It had the largest competence score for the sample but one of the lowest scores on warmth. Cluster 1 and 4 had similar warmth ratings and did not significantly differ from one another $(\phi=0.171)$, while they differed from all the other clusters on warmth (all comparisons $p=0.000$ ). Clusters 2,3 and 5 did not significantly differ from each other in warmth, and they had warmth scores that could be considered as scores in the lower end in our sample. Competence scores did not follow the same pattern. Clusters 1, 2 and 3 did not significantly differ from one another in competence ratings and showed scores in the middle of the scale. Cluster 2 differed significantly from all other clusters on competence, having the lowest score of the sample, while the opposite was true for Cluster 5, which showed the highest competence score that differed from the other clusters. Although all the categories did not perfectly match on completely distinctive clusters, some strong differences and similarities of clustered occupations emerged, which is in line with previous SCM research (e.g. Fiske et al., 2002).

\section{Mixed stereotypes}

Paired sample $t$-tests were conducted to test for differences between warmth and competence ratings for each occupation. The rationale for this approach was to explore mixed stereotypes on the individual level (Table 3). Out of 22 groups, 19 had statistically significant differences. Significantly higher warmth than competence was found for the following occupations: assistant nurse*, cleaning staff, staff nurse, office assistants and secretaries*, restaurant waiting staff*, preschool teacher and personal assistants*. Significantly, higher competence 


\section{PR}

51,2

\begin{tabular}{|c|c|c|c|}
\hline Group & $\begin{array}{l}\text { Mean paired differences } \\
\text { (warmth- competence rating) }\end{array}$ & $t$ & $p$ \\
\hline $\begin{array}{l}\text { Assistant nurse, home-help service, home health } \\
\text { nursing, retirement home workers }\end{array}$ & 0.965 & 9.16 & 0.000 \\
\hline Salesperson & -0.438 & -3.92 & 0.000 \\
\hline Surgeon & -1.412 & -11.74 & 0.000 \\
\hline Engineer & -1.415 & -14.61 & 0.000 \\
\hline Chef & -0.469 & -5.64 & 0.000 \\
\hline Store manager & -0.169 & -2.02 & 0.047 \\
\hline Warehouse worker & 0.123 & 1.41 & 0.164 \\
\hline Assistant accountant & -0.140 & -1.41 & 0.164 \\
\hline High-school teacher & -0.031 & -0.39 & 0.698 \\
\hline Cleaning staff & 0.583 & 5.68 & 0.000 \\
\hline Mechanic & -0.508 & -6.11 & 0.000 \\
\hline Accountant & -1.258 & -12.04 & 0.000 \\
\hline Staff nurse & 0.419 & 4.89 & 0.000 \\
\hline Carpenter & -0.585 & -7.71 & 0.000 \\
\hline Heavy machinery operator & -0.658 & -6.71 & 0.000 \\
\hline Office assistants and secretaries & 0.285 & 3.03 & 0.004 \\
\hline Truck driver & -0.231 & -3.66 & 0.001 \\
\hline Researcher & -1.963 & -16.58 & 0.000 \\
\hline Systems and software developer & -1.668 & -13.23 & 0.000 \\
\hline Restaurant waiting staff & 0.758 & 8.73 & 0.000 \\
\hline Preschool teacher & 0.877 & 8.14 & 0.000 \\
\hline Personal assistants & 1.156 & 10.26 & 0.000 \\
\hline
\end{tabular}

Table 3.

Matched pair $t$-test comparing warmth and competence for individual occupations

Note(s): Degrees of freedom equal to 64 except for one occupation personal assistants $\mathrm{df}=63$ )

was found for the following: salesperson*, surgeon*, engineer*, chef*, store manager*, mechanic*, accountant*, carpenter*, heavy machinery operator*, truck driver, researcher* and systems and software developer*. No differentiation was found for the following: warehouse worker, assistant accountant and high school teacher. When cluster and individual mixed stereotype indications are combined, 15 groups have a mixed stereotype solution on both levels [4]. This is in line with previous SCM research where the majority of tested categories have mixed stereotype content.

Comparative scores for warmth and competence of occupational categories

Confidence intervals are plotted and examined for each occupational category to provide further comparisons between and within each cluster. Warmth and competence are considered separately to allow for more precise comparisons among occupations on each dimension. The order of groups is based on their cluster membership, presenting first occupations that belong to the clusters highest on the dimension. Comparing the two plots visually, it is evident that the clusters do distinguish sets of groups that differ on the tested dimensions (Figures 2 and 3). Warmth scores showed less diversification among groups belonging to different clusters. The grand mean for warmth ratings for the full sample is $M=3.17$, and the corresponding grand mean for the competence ratings is $M=3.43$. Comparing clusters and their mean scores to the grand means can be another way of comparing and validating the different cluster solutions and individual group scores. Cluster 1 , identified as having higher warmth $(M=3.78)$ than competence $(M=3.15)$, had a higher score than the grand mean on warmth and a lower score than the grand mean on competence. Cluster 5, identified as having higher competence $(M=4.29)$ than warmth $(M=2.74)$, showed the same pattern when compared to the grand mean. Cluster 2, identified as the low-low 


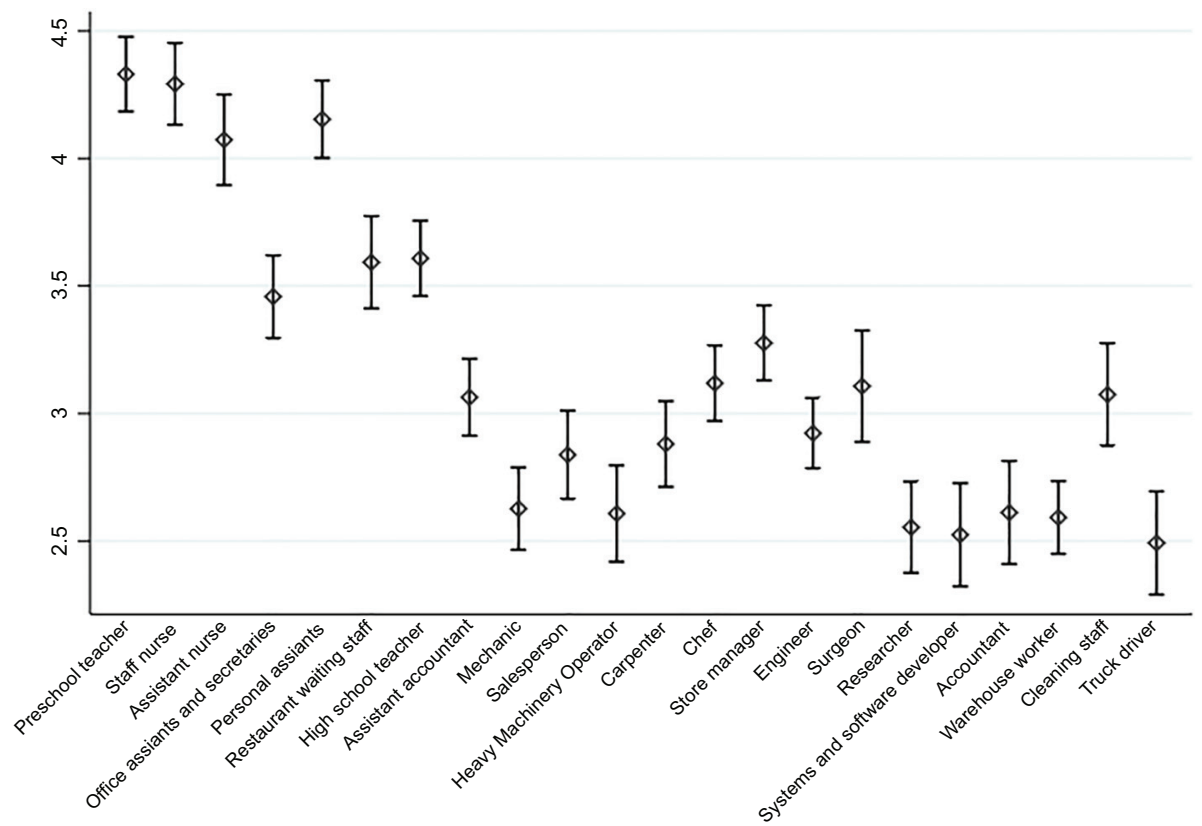

Note(s): Categories within the cluster highest on warmth presented first
Occupational stereotypes

613

cluster, has mean scores below the grand mean for each dimension and Cluster 4, identified as the high-high cluster, had higher scores than average on both dimensions. Cluster 3, identified as having significantly higher competence $(M=3.34)$ than warmth $(M=2.92)$, appeared closest to the grand mean, which suggests a mid-cluster solution. Analyzing the proximity of the clusters to the grand mean confirms the placement of cluster solutions. They could also be useful in interpreting individual comparisons among groups.

\section{Discussion}

One of the main questions of this study was whether one could rely on the SCM to capture the stereotype content of preselected occupations in a professional sample in a European country (Sweden). Out of 22 occupations, 21 had two factors emerging that corresponded to the warmth and competence dimensions. Out of the 22 groups, 19 presented mixed stereotypes on the individual level, and the range of diversification on both dimensions was similar to prior SCM research (Fiske et al., 2002). These results indicate that many of the characteristics typically found in SCM explorations appear in the current context too. Some differences to previous research did emerge, however. These differences are discussed in relation to Fiske and Dupree's (2014) study as this is, to our knowledge, the only study that has followed the typical SCM procedure, tested theoretical assumptions of the SCM and clustered occupations along the warmth and competence dimensions. In the current study, a five-cluster solution was deemed most descriptive of the data. Fiske and Dupree (2014) found a four-cluster solution for their occupational groups. However, in one of their studies on perceived warmth and competence of social groups, Fiske et al. (2002) found support for a five-cluster solution. The fifth cluster contained groups that were positioned in the middle of the warmth/ competence space and did not differ statistically in their perceived warmth and competence. 
$\mathrm{PR}$
51,2

\section{4}

Figure 3.

Mean competence ratings for occupations

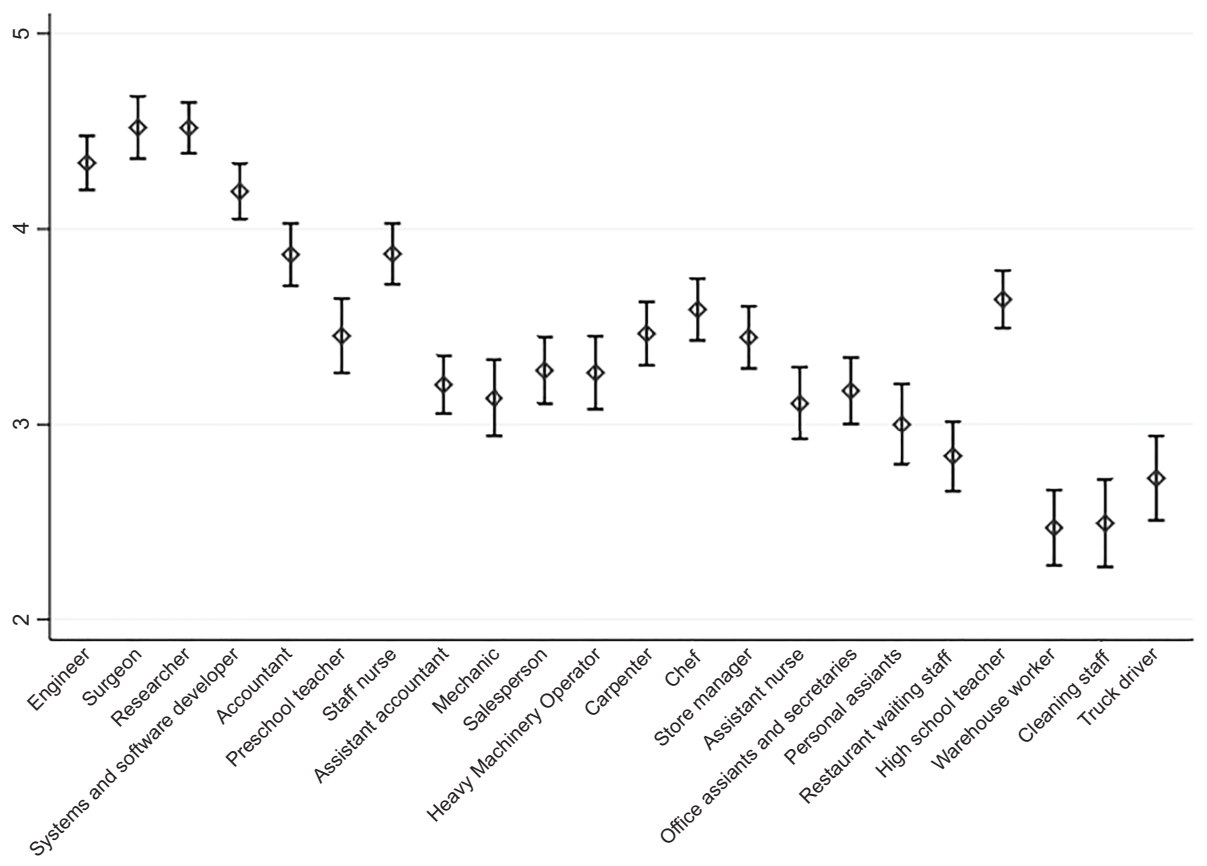

Note(s): Categories within the cluster highest on competence presented first

Similarly, Cluster 3 was the closest to the grand mean results and the middle of the warmth/ competence space although both its warmth and competence scores are below the grand mean score for both ratings. The middle cluster solution was higher in competence than warmth, as well as the overall grand mean results point to a higher competence score. This larger distinctiveness on the competence dimension could be due to this dimension being more salient either because it is more relevant to perceptions of occupations or because the participants in the current study mostly consisted of recruiters to whom competence might be more central compared to the student or MTurk participants studied in previous research on occupational stereotypes. In the current data, something similar to the higher warmth/lower competence corner emerges. Cluster 1 (assistant nurse, office assistants and secretaries, personal assistant, restaurant waiting staff and high-school teacher) showed significantly higher warmth than competence although the cluster did not differ entirely from all other clusters. Fiske and Dupree (2014) did not find a pity corner (higher warmth than competence) and hypothesized that this corner belongs to perceptions of the unemployed. A couple of occupations that fell in the low-low cluster in Fiske and Dupree (2014) ended up in this cluster. Despite the different cluster solutions that were found, most of the occupational category positioning and scores were similar to the Fiske and Dupree (2014) study.

\section{Implications for hiring discrimination research}

The current results should be of relevance for future research on hiring discrimination. They have implications for correspondence tests with the purpose of exploring possible matching effects between the stereotype content of social groups and occupations. Regarding mixed stereotypes, it is possible that social groups face discriminatory treatment when applying for 
occupations that are associated with the dimension in which the group is perceived as lacking and favorable treatment when applying for occupations associated with the dimension in which the group is perceived to be high. To illustrate, job applicants belonging to Asian minority groups (low warmth and high competence; Fiske et al., 2002) may have a more difficult time in getting a job as a preschool teacher than those with an ethnic background stereotyped as warm but not so competent (e.g. Greeks; Carlsson et al., 2012), whereas the opposite may be true for an engineering job. The current results should provide guidance with respect to the selection of warmth/competence occupations to be included in a future correspondence test on matching effects.

Thus far correspondence tests have typically relied on other criteria when selecting occupations, such as male- versus female-dominated occupations, skill-level or educational requirements (e.g. Carlsson 2011, Ahmed et al., 2013, and Carlsson et al., 2014). Arguably, these criteria are much narrower in scope than warmth and competence. Whereas the maleversus female-dominated occupational distinction is useful for studying gender stereotypes (Carlsson et al., 2014) or stereotypes that incorporate masculinity/femininity traits (e.g. sexual orientation; Ahmed et al., 2013), it is less useful in the context of most other stereotypes (e.g. race/ethnicity, age and disability). Likewise, while skill level is arguably an important criterion that is incorporated in the competence dimension in the language of the SCM, it is silent with respect to job requirements that incorporate warmth (e.g. social skills and empathy). The current findings set the stage for an examination of theoretically grounded matching effects that cover a more comprehensive set of stereotypes based on warmth and competence.

Note that the proposed correspondence tests differ from the methodological approach used in previous research on the relationship between occupational segregation and incongruence between stereotypes of social groups and occupations. For example, whereas He et al. (2019) strictly rely on correlation by mapping their occupational stereotype classification onto demographic stereotypes to predict occupational segregation (in the United States), correspondence tests experimentally manipulate (otherwise equal) applicants' social group membership (e.g. gender). Thus, correspondence tests provide evidence of discrimination (e.g. women receive fewer callbacks in high competence occupations) rather than relying completely on differences that already exist (e.g. fewer women employees in occupations associated with high competence).

\section{Implications for HRM}

The current research has numerous implications for HRM. Concerning impression management, certain occupational groups should benefit from stressing attributes which the stereotype implies they are lacking. For example, it may be particularly important for surgeons (high competence and low warmth) to display warmth behaviors (e.g. empathy) when discussing an upcoming surgery with the patient. This does not mean that competence behaviors should be ignored. After all, they are central to the context. What this does mean is that there might be a more urgent need for the surgeon to display warmth behaviors to gain the patient's trust since the surgeon's competence is already taken for granted (until proven otherwise) due to the occupational stereotype.

Hiring is another context where occupational stereotypes may matter. An applicant applying for a new job in a different occupational category should consider how the stereotype content of the previous category matches that of the new category. A cleaner (low warmth) who now applies for a waitressing job would probably want to stress warmth related attributes in the resume and during the interview because such attributes are associated with waitressing. If the competing applicant is an office assistant (high warmth), this would be even more urgent.
Occupational stereotypes 
PR

51,2

\section{6}

Performance appraisals may be another context where occupational stereotypes may matter. It is possible that when organizations assess employee performance in various occupational groups, bias could occur when the performance dimension relates to the occupational stereotype content. Thus, high ratings of collaboration skills may be harder to achieve for accountants than for office secretaries (all else being equal) due to inherent differences in perceived warmth, which incorporates how well one gets along with others. The risk of bias should be greater when more subjective measures are used, for example, in conjunction with rating scales with vaguely defined assessment criteria. Occupational stereotypes may also extend to promotions, with employees from certain occupational groups having a more difficult time being promoted for positions requiring attributes which do not match the stereotype content of the employees' current occupation.

Arguably, employers' warmth and competence perceptions may be accurate at the group level. However, because substantial research suggests that stereotypes translate into discrimination where identical performance is evaluated differently due to social group membership (e.g. Agerström and Rooth, 2011), one could expect employees to be discriminated based on their occupational group membership too.

\section{Limitations and future directions}

Participants in the current research consisted of a convenience sample with working professionals (mostly recruiters) from different industries, company sizes and physical locations. It is thus unclear to what extent our sample is representative of a wider working population in Sweden.

The current research focus was on explicit, deliberately reported stereotypes, which always carry the possibility of social desirability affecting the results. To limit social desirability, however, we decided to measure perceived (cultural) stereotypes instead of personally endorsed. While it is not clear how accurate these perceptions are, our results are highly consistent with those of previous research using this approach when studying occupational stereotypes.

Warmth and competence stereotypes have been found to also exist on the implicit level (Carlsson and Björklund, 2010). One fruitful avenue for future research would be to investigate implicit occupational stereotypes (that is, automatic associations that are relatively inaccessible to conscious awareness and/or control). It would be interesting to examine how strongly people associate warmth and competence attributes with some of the occupations that appeared in the different clusters in the current study and to learn how well implicit occupational stereotypes correspond to explicit ones. Another interesting research question would be to examine to what extent occupational segregation (e.g. gender) is related to incongruences between implicit demographic and occupational stereotypes, as compared to incongruences between explicit demographic and occupational stereotypes, which constituted the focus in the He et al. (2019) study.

Another limitation lies in the cluster analysis. The aim of the study was not to investigate social structural correlates or associated emotions, which left the clustering process without external variables to validate the solutions. To account for this, we compared several potential solutions, and according to the recommendations of Hair et al. (2019), we changed the order of the stimuli entered in the cluster analysis, and reasonable stability across solutions could be inferred. The research is also based on a theoretical framework of SCM, which has been subjected to 20 years of research and confirmed cross-culturally on different levels of analysis and rated entities. According to Hair et al. (2019), theoretical guidance may be necessary to be able to rely on the results of the cluster analysis. Thus, the results were compared to previous research and showed mostly similar results. Yet, to our knowledge, this 
is only the second study that has explicitly tested the SCM in the context occupational stereotypes with a systematic focus on warmth and competence, using cluster analysis to identify occupational category positioning.

As we did not ask the participants to come up with occupations that they personally found relevant and did not measure perceived social status, competition or the emotional correlates of clusters, we cannot conclude that all aspects of the model replicate. Future research on occupational stereotype content may therefore, for example, want to investigate whether (high) competence follows from perceived (high) occupational status/prestige and whether (low) warmth follows from perceived (high) competition within an occupation, as would be predicted by the SCM (Fiske et al., 2002). Nevertheless, this study provides insight into how numerous common occupations in the labor market are perceived and compare to one another, whether a two-factorial structure emerges including the position of the occupations within the warmth/competence space and whether specific occupations have mixed stereotype content.

\section{Concluding remarks}

We conclude that warmth and competence seem to constitute fundamental stereotype content, which working professionals associate with common occupations in the labor market. The finding that the SCM can be used to parsimoniously account for occupational stereotypes in a European country lends further empirical support to the universality of the model. The current findings provide a useful departure point for future research interested in examining how job candidates and employees from various social groups are evaluated in relation to occupations associated with warmth and competence as well as how social and occupational stereotypes interact to produce discrimination in the labor market.

\section{Notes}

1. Some adjustments to the items used in Cuddy et al. (2009) were made. In competence subscale, the attributes "confident" and "capable" were replaced by "talented" and "ambitious". In warmth subscale, the attribute "sincere" was replaced by "considerate". The specific warmth and competence items used in the current study have demonstrated good psychometric properties in a previous study (Agerström, 2014) on Swedish professional recruiters' warmth and competence perceptions in the workplace. In Swedish, the warmth attributes were "vänlig", "varm", "välmenande", "omtänksam" and the competence items were "kompetent", "begåvade", "skicklig", "ambitiös".

2. This study was a part of larger data collection session where participants also rated the perceived warmth and competence of different combinations of demographic group categories (intersected on ethnicity, gender, sexual orientation and age). These data are reported in a separate study by Strinic et al. (2020) with a different research question. Occupational stereotype data are only reported in the current study.

3. Cluster names do not indicate specific order but are used for a clear presentation of results.

4. Groups with mixed stereotype ratings on both individual and cluster membership levels are marked with "*” in the text.

\section{References}

Agerström, J. (2014), "Why does height matter in hiring?", Journal of Behavioral and Experimental Economics, Vol. 52, pp. 35-38, doi: 10.1016/j.socec.2014.06.002.

Agerström, J. and Rooth, D. (2011), "The role of automatic obesity stereotypes in real hiring discrimination”, Journal of Applied Psychology, Vol. 96 No. 4, pp. 790-805, doi: 10.1037/a0021594. 
PR

51,2

\section{8}

Ahmed, A.M., Andersson, L. and Hammarstedt, M. (2013), “Are gay men and lesbians discriminated against in the hiring process?”, Southern Economic Journal, Vol. 79 No. 3, pp. 565-585, doi: 10. 4284/0038-4038-2011.317.

Baert, S. (2018), "Hiring discrimination: an overview of (almost) all correspondence experiments since 2005”, in Gaddis, M.S. (Ed.), Audit Studies: Behind the Scenes with Theory, Method, and Nuance, Springer International Publishing, Cham, pp. 63-77, doi: 10.1007/978-3-319-71153-9_3.

Booth, A. and Leigh, A. (2010), "Do employers discriminate by gender? A field experiment in femaledominated occupations", Economics Letters, Vol. 107 No. 2, pp. 236-238, doi: 10.1016/j.econlet. 2010.01.034.

Bye, H.H., Herrebrøden, H., Hjetland, G.J., Røyset, G.Ø. and Westby, L.L. (2014), "Stereotypes of Norwegian social groups", Scandinavian Journal of Psychology, Vol. 55 No. 5, pp. 469-476, doi: 10.1111/sjop.12141.

Carlsson, M. (2011), "Does hiring discrimination cause gender segregation in the Swedish labor market?", Feminist Economics, Vol. 17 No. 3, pp. 71-102, doi: 10.1080/13545701.2011.580700.

Carlsson, R. and Björklund, F. (2010), "Implicit stereotype content: mixed stereotypes can be measured with the implicit association test", Social Psychology, Vol. 41 No. 4, pp. 213-222, doi: 10.1027/ 1864-9335/a000029.

Carlsson, R., Björklund, F. and Bäckström, M. (2012), “Mixed discriminatory judgments of individuals' warmth and competence-related abilities", Social Psychology, Vol. 43 No. 3, pp. 160-167, doi: 10. 1027/1864-9335/a00009.

Carlsson, R., Agerström, J., Björklund, F., Carlsson, M. and Rooth, D.O. (2014), “Testing for backlash in hiring", Journal of Personnel Psychology, Vol. 13 No. 4, pp. 204-214, doi: 10.1027/1866-5888/ a000126.

Cuddy, A.J.C., Fiske, S.T., Kwan, V.S.Y., Glick, P., Demoulin, S., Leyens, J., Bond, M.H., Croizet, J., Ellemers, N., Sleebos, E., Htun, T., Kim, H., Maio, G., Perry, J., Petkova, K., Todorov, V., Rodriguez-Bailon, R., Morales, E., Moya, M., Palacios, M., Smith, V., Perez, R., Vala, J. and Ziegler, R. (2009), "Stereotype content model across cultures: towards universal similarities and some differences", British Journal of Social Psychology, Vol. 48 No. 1, pp. 1-33, doi: 10.1348/014466608X314935.

Derous, E., Nguyen, H.H. and Ryan, A.M. (2009), "Hiring discrimination against Arab minorities: interactions between prejudice and job characteristics", Human Performance, Vol. 22 No. 4, pp. 297-320, doi: 10.1080/08959280903120261.

Derous, E., Ryan, A.M. and Serlie, A.W. (2015), "Double Jeopardy upon Resumé screening: when Achmed is less employable than Aïsha", Personnel Psychology, Vol. 68 No. 3, pp. 659-696, doi: 10.1111/peps.12078.

Derous, E., Pepermans, R. and Ryan, A.M. (2017), "Ethnic discrimination during résumé screening: interactive effects of applicants' ethnic salience with job context", Human Relations, Vol. 70 No. 7, pp. 860-882, doi: 10.1177/0018726716676537.

Eagly, A.H. and Wood, W. (2012), "Social role theory", in van Lange, P., Kruglanski, A. and Higgins, E.T. (Eds), Handbook of Theories in Social Psychology, Sage Publications, pp. 458-476, doi: 10. 4135/9781446249222.n49.

Farber, H.S., Silverman, D. and Von Wachter, T.M. (2017), "Factors determining callbacks to job applications by the unemployed: an audit study", The Russell Sage Foundation Journal of the Social Sciences, Vol. 3 No. 3, pp. 168-201, doi: 10.7758/RSF.2017.3.3.08.

Fiske, S.T. and Dupree, C. (2014), "Gaining trust as well as respect in communicating to motivated audiences about science topics", Proceedings of the National Academy of Sciences, Vol. 111 No. Supplement 4, pp. 13593-13597, doi: 10.1073/pnas.1317505111.

Fiske, S.T., Xu, J., Cuddy, A.C. and Glick, P. (1999), “(Dis)respecting versus (Dis)liking: status and interdependence predict ambivalent stereotypes of competence and warmth”, Journal of Social Issues, Vol. 55 No. 3, pp. 473-489, doi: 10.1111/0022-4537.00128.

Fiske, S.T., Cuddy, A.J.C., Glick, P. and Xu, J. (2002), "A model of (often mixed) stereotype content: competence and warmth respectively follow from perceived status and competition", Journal 
of Personality and Social Psychology, Vol. 82 No. 6, pp. 878-902, doi: 10.1037/0022-3514.82. 6.878.

Fiske, S.T., Cuddy, A.J.C. and Glick, P. (2007), "Universal dimensions of social cognition: warmth and competence", Trends in Cognitive Sciences, Vol. 11 No. 2, pp. 77-83, doi: 10.1016/j.tics.2006.11.005.

Goldberg, C.B., Finkelstein, L.M., Perry, E.L. and Konrad, A.M. (2004), "Job and industry fit: the effects of age and gender matches on career progress outcomes", Journal of Organizational Behavior, Vol. 25 No. 7, pp. 807-829, doi: 10.1002/job.269.

Hair, J.F., Black, W.C., Babin, J.B. and Andersson, R.E. (2019), Multivariate Data Analysis, 8th ed., Cengage learningEMEA, Hampshire.

He, J.C., Kang, S.K., Tse, K. and Toh, S.M. (2019), "Stereotypes at work: occupational stereotypes predict race and gender segregation in the workforce", Journal of Vocational Behavior, Vol. 115, p. 103318, doi: 10.1016/j.jvb.2019.103318.

Imhoff, R., Woelki, J., Hanke, S. and Dotsch, R. (2013), "Warmth and competence in your face! Visual encoding of stereotype content”, Frontiers in Psychology, Vol. 4, p. 386, doi: 10.3389/fpsyg. 2013.00386.

Imhoff, R., Koch, A. and Flade, F. (2018), "(Pre) occupations: a data-driven model of jobs and its consequences for categorization and evaluation", Journal of Experimental Social Psychology, Vol. 77, pp. 76-88, doi: 10.1016/j.jesp.2018.04.001.

Kervyn, N., Fiske, S.T. and Malone, C. (2012), "Brands as intentional agents framework: how perceived intentions and ability can map brand perception", Journal of Consumer Psychology, Vol. 22 No. 2, pp. 166-176, doi: 10.1016/j.jcps.2011.09.006.

King, E.B., Mendoza, S.A., Madera, J.M., Hebl, M.R. and Knight, J.L. (2006), "What's in a name? A multiracial investigation of the role of occupational stereotypes in selection decisions", Journal of Applied Social Psychology, Vol. 36 No. 5, pp. 1145-1159, doi: 10.1111/j.0021-9029.2006.00035.x.

Koenig, A.M. and Eagly, A.H. (2014), "Evidence for the social role theory of stereotype content: observations of groups' roles shape stereotypes", Journal of Personality and Social Psychology, Vol. 107 No. 3, pp. 371-392, doi: 10.1037/a0037215.

Krings, F., Sczesny, S. and Kluge, A. (2011), "Stereotypical inferences as mediators of age discrimination: the role of competence and warmth", British Journal of Management, Vol. 22 No. 2, pp. 187-201, doi: 10.1111/j.1467-8551.2010.00721.x.

Ruggs, N.E., Hebl, M.R., Singletary Walker, S. and Fa-Kaji, N. (2014), "Selection biases that emerge when age meets gender”, Journal of Managerial Psychology, Vol. 29 No. 8, pp. 1028-1043, doi: 10. 1108/JMP-07-2012-0204.

Strinić, A., Carlsson, M. and Agerström, J. (2020), "Multiple-group membership: warmth and competence perceptions in the workplace”, Journal of Business and Psychology, pp. 1-18, doi: 10. 1007/s10869-020-09713-4.

Statistics Sweden (2015), “The Swedish occupational register with statistics 2015”, (Report No. AM 33 SM 1701), available at: https://www.scb.se/contentassets/982742930b774ff49ba5a7056d069992/ am0208_2015a01_sm_am33sm1701.pdf.

Weichselbaumer, D. (2016), "Discrimination against migrant job applicants in Austria: an experimental study”, German Economic Review, Vol. 18 No. 2, pp. 237-265, doi: 10.1111/geer.12104.

\section{Corresponding author}

Andrea Strinić can be contacted at: andrea.strinic@lnu.se

For instructions on how to order reprints of this article, please visit our website:

www.emeraldgrouppublishing.com/licensing/reprints.htm

Or contact us for further details: permissions@emeraldinsight.com
Occupational stereotypes 